\title{
DOI 10.26886/2414-634X.8(17)2017.6
}

UDC: $662.998-492$

INVESTIGATIONS OF THE INFLUENCE OF THE TECHNOLOGICAL MODES OF MANUFACTURE OF PENOKERAMIC INSULATION PANELS

IN THE MICROWAVE FIELD

${ }^{1} M$. T. Zhuginisov, ${ }^{2}$ V. P. Selyaev, ${ }^{1,3 *}$ R. E. Nurlybaev, ${ }^{1}$ E. S. Orynbekov, ${ }^{1}$ A. A. Djoldasov, ${ }^{3}$ S. A. Yakupbaev, ${ }^{3}$ A. A. Iskakov, ${ }^{1}$ A. A. Murzagulova

${ }^{1}$ Kazakh National Research Technical University named after K. I. Satpaev, 22 Almaty, Republic of Kazakhstan

2 "National Research Mordovian State University. N. P. Ogareva, Saransk, Russia

${ }^{3}$ Limited Liability Partnership SAVENERGY Almaty, Republic of Kazakhstan

In modern technologies, high frequency (HF) and ultrahigh frequency (UHF) currents are widely used for heating and drying various materials in many industries [1, 2]. However, this method has not been used to form cellular structures. The presence of a simple method of obtaining a porous structure, by bringing solutions to boiling excess moisture in the fields of $H D$ and microwave, will make it possible to improve industrial production, reduce electricity consumption, and reduce the cost of components, etc. [2, 3].

Keywords: foam ceramics, diatomite, termal insulation, microsilica, solgel method.

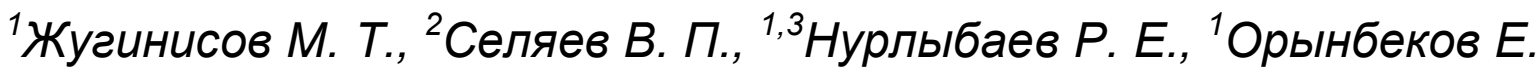
C., ' Джолдасов А. А., ${ }^{3}$ Якупбаев С. А., ${ }^{3}$ Искаков А. А., ${ }^{1}$ Мурзагулова А. A. Исследования влияния технологических режимов изготовления пенокерамических изоляционных панелей в свч - поле / ${ }^{1}$ «Казахский 
национальный исследовательский технический университет имени К. И. Сатпаева», г. Алматы, Республика Казахстан, ${ }^{2}$ «Национальный исследовательский Мордовский государственный университет им. Н. П. Огарева», г. Саранск, Россия, ${ }^{3}$ Товарищество с ограниченной ответственностью «SAVENERGY»,

В современных технологиях широко используют токи высокой частоты (ТВЧ) и сверхвысокой частоты (СВЧ) для нагрева и сушки различных материалов во многих отраслях промышленности [1, 2]. Однако для фрормирования ячеистых структур этот метод до настоящего времени не применялся. Наличие простого метода получения пористой структуры, путем доведения растворов до выкипания избыточного количества влаги в полях ТВЧ и СВЧ даст возможность улучшить индустриальность производства, сократить расход электроэнергии, удешевить компоненты т.

Ключевые слова: пенокерамика, диатомит, теплоизоляция, микрокремнезем, золь-гель метод.

Введение. Известно, что нагрев материалов в электрическом поле высокой частоты осуществляется за счет преобразования энергии электромагнитного воля в эквивалентное количество теплоты - это пример микроволновой печи, в которой электрическая энергия постоянного тока преобразуется в энергию электромагнитного поля сверхвысокой частоты [4-5].

Экспериментальная часть. Для проведения экспериментов с целью получения пористых структур из диатомитов и цеолитосодержащих пород использовалась СВЧ-печь со следующими характеристиками: 1) источник питания 220V переменного тока, 50 Гц; 2) частота микроволн 2,450МГц; 3) выходная мощность (по стандарту IEC607050) 800 Вт; 4) потребляемая мощность 1200 Вт. 
В качестве материалов применяемых для исследования была использована цементные, диатомитовые, цеолитосодержащие суспензии. Количество фрракций частиц принимали равным двум т.к. для получения высоких теплоизоляционных свойств дисперсных порошков необходимо повысить пористость системы до 95\% рисунок 1.

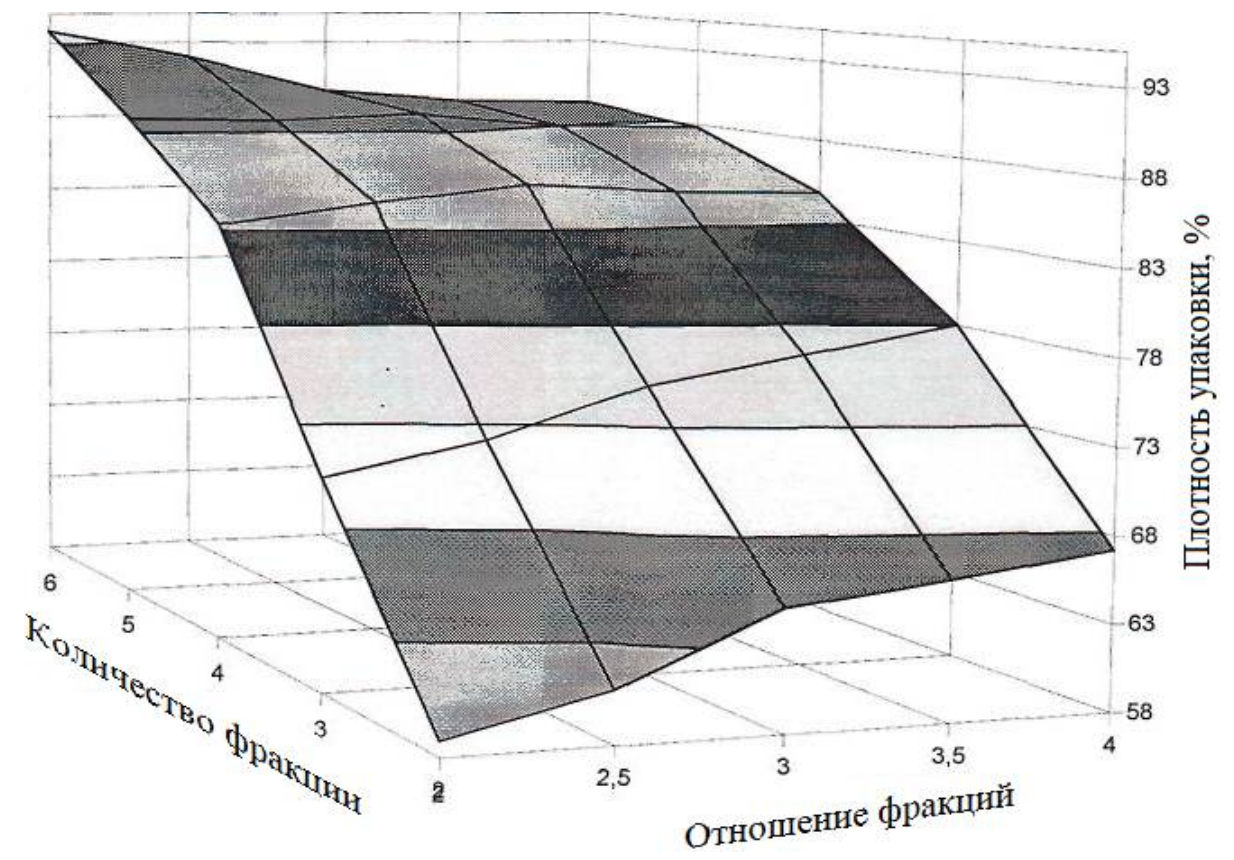

Рис. 1. Зависимость изменения плотности дисперсного порошка от размерного отношения фракций

При нагреве дисперсных порошков, содержащих несколько фракций с определенной начальной влажностью, максимальное давление выше в зернах (частицах) меньшего диаметра, так как с уменьшением размера частиц уменьшается коэфрфициент фильтрации.

Для проведения эксперимента необходимо было теоретически определить изменение температуры и влажности от длительности нагрева и сравнить их с фрактическими, полученными в результате эксперимента. Результаты теоретических расчетов и экспериментальных данных представлены в таблице 1. 
Изменение температуры от длительности нагрева в СВЧ - поле

\begin{tabular}{|c|c|c|}
\hline Время нагрева т, сек & Расчетная температура $\mathrm{t}, \%$ & Фактическая температура $\mathrm{t}$, \\
\hline 5 & 28,5 & 29 \\
\hline 10 & 33 & 34 \\
\hline 20 & 38,5 & 40 \\
\hline 30 & 44 & 45,5 \\
\hline 40 & 50 & 51 \\
\hline 50 & 57,5 & 60 \\
\hline 60 & 66,5 & 67 \\
\hline 70 & 76,5 & 79 \\
\hline 80 & 89 & 92 \\
\hline 90 & 101 & 100 \\
\hline
\end{tabular}

Избыточное давление при испарении влаги, необходимое для фрормирования пористой структуры осуществляется с потерей В/Ц, что влияет на структуру и

прочностные характеристики.

Потеря влаги начнется с момента достижения водой в объеме дисперсной системы температуры $100^{\circ} \mathrm{C}$. Значения средней влажности дисперсной системы в определенные моменты времени нагрева, полученные экспериментально и рассчитанные по приближенной формулы приведены в таблице 2.

Учитывая, что на структуру порового пространства исследуемого материала большое влияние оказывают технологические параметры изготовления, такие как -фрильтрация пара, состав, сроки выдерживания дисперсной системы перед обработкой СВЧ - полями, количество воды, количество фрракций наполнителя и их размер, рассмотрены методы контроля процесса формирования поровых структур. 
Таблица 2

Изменение значений средней влажности дисперсной системы от длительности нагрева в поле СВЧ

\begin{tabular}{|c|c|c|c|}
\hline № состава & Время нагрева $\tau$, сек & Расчетная средняя & Фактическая \\
\hline 1 & 35 & 1 & 1 \\
\hline 2 & 45 & 0,98 & 0,99 \\
\hline 3 & 55 & 0,967 & 0,97 \\
\hline 4 & 65 & 0,95 & 0,95 \\
\hline 5 & 75 & 0,94 & 0,94 \\
\hline 6 & 85 & 0,925 & 0,92 \\
\hline 7 & 95 & 0,913 & 0,91 \\
\hline 8 & 105 & 0,906 & 0,899 \\
\hline 9 & 115 & 0,899 & 0,891 \\
\hline 10 & 125 & 0,89 & 0,88 \\
\hline
\end{tabular}

Предлагаемый процесс фрормирования ячеистой структуры высокоинтенсивен, поэтому требует высокоточных средств контроля и управления. Для анализа процессов образования поровой структуры нами предложено использовать метод акустической эмиссии. Звуковые импульсы, возникающие при образовании паровых пузырьков регистрировались при помощи электретного микрофрона, подающего сигнал на вход звуковой карты компьютера.

Принимаемый сигнал преобразуется встроенным кодеком звуковой карты с частотой дискретизации 44.1 КГц, 16 бит, моно. Такой частоты оказалось достаточно для анализа спектра шумов, излучаемых при кипении.

Результаты обрабатывались при помощи широко распространенного музыкального редактора Cool Edit Pro, что оказалось достаточно, чтобы анализировать происходящий процесс. Встроенный анализатор программы Cool Edit Pro позволяет в реальном времени фриксировать появление высокочастотных шумов, сопровождающих структурообразование, что позволило различить технологические шумы (шумы от печи и др. техники) от шумов кипения. Для фрильтрации сигнала с отбрасыванием низкочастотной фоновой 
составляющей, которая осуществляется программно, в Cool Edit Pro представлена масса возможных алгоритмов. Визуально процесс легко контролировать при использовании спектрального представления виброграммы, когда интенсивность сигнала отмечается различными цветами Рис 2.

Известно, что во время кипения пузырьки пара издают звук, интенсивность которого зависит от температуры исследуемого вещества. Полученный энергетический спектр звукового шума (рис. 3) показывает, как изменяется звуковое давление при формировании ячеистой структуры в режиме кипения. Это позволяет контролировать образование порового пространства при применении различных режимов формования.

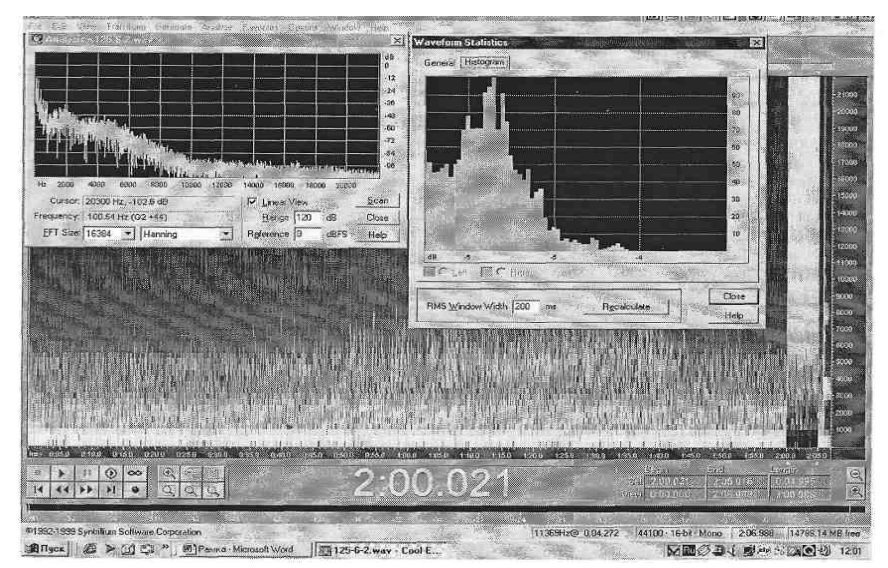

Рис. 2. Работа программы во время

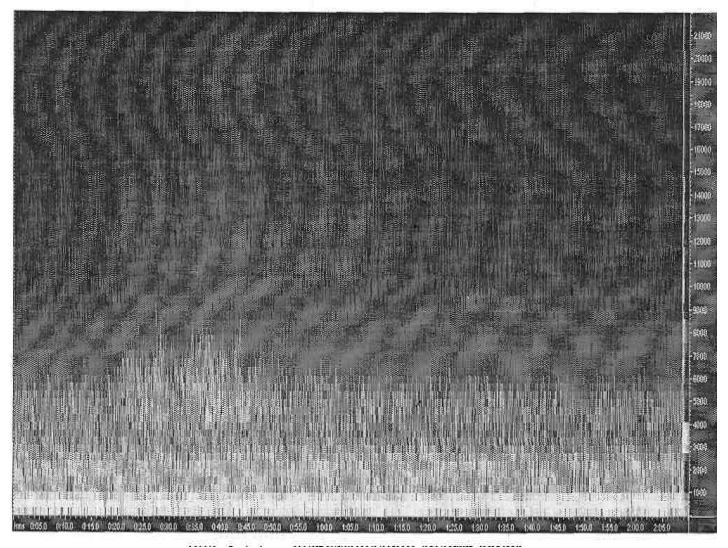

Рис. 3. Энергетический спектр звука измерения характеристик каустической

\section{эмиссии}

В зависимости от, области использования получаемого пористого материала, можно регулировать параметры его порового пространства, так как для теплоизоляционных материалов необходимо иметь большее количество закрытых пор, а отделочных звукопоглощающих материалов больше - открытых пор. Для контроля порообразования был получен график зависимости образования пористости (\%) и давления звука от времени формования (рис. 4, рис. 5.). 


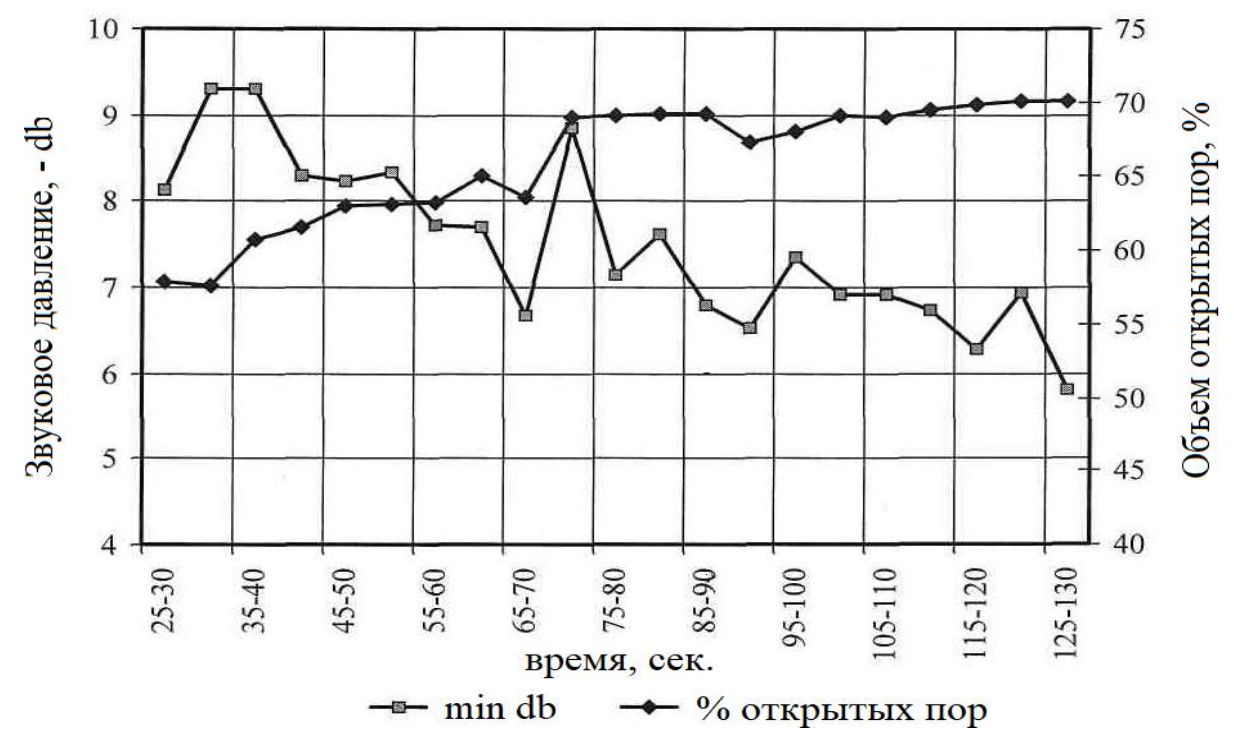

Рис. 4. Звуковое давление и образование открытых пор во время нагрева

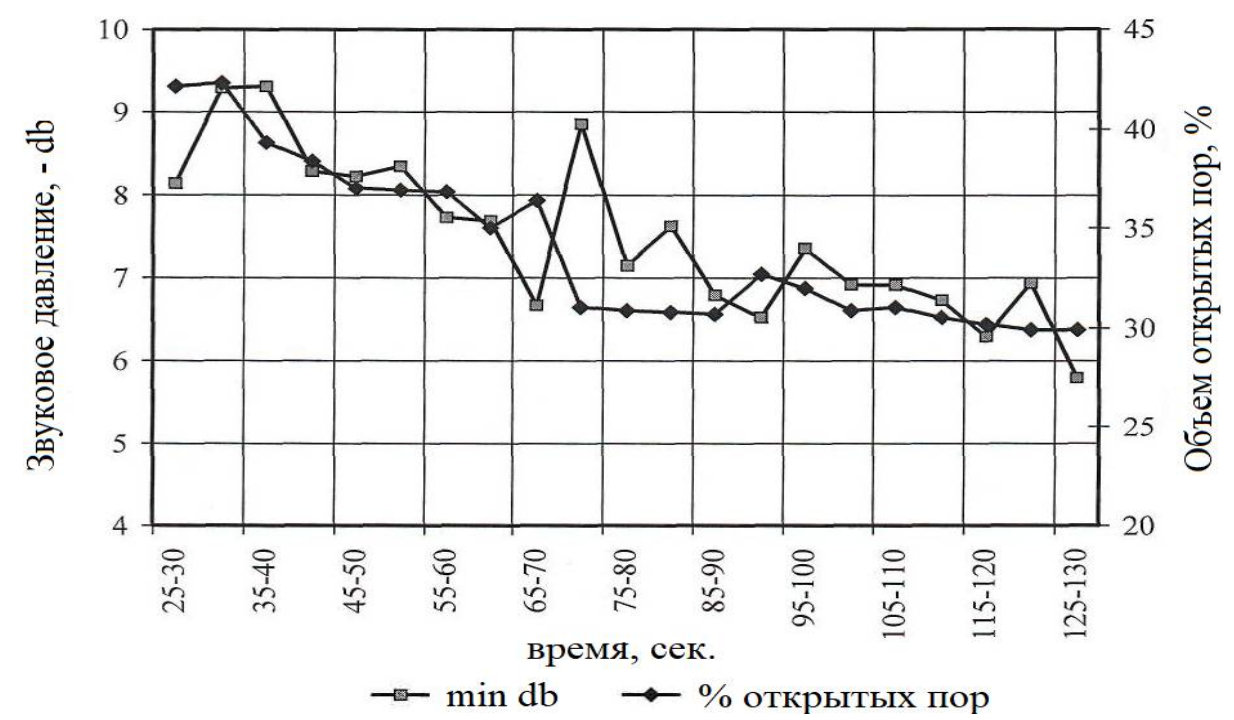

Рис. 5. Звуковое давление $(\mathrm{db})$ и образование закрытых пор во время нагрева

Данный метод контроля позволяет использовать средний температурный режим системы не превышающий оптимальной температуры гидратации при СВЧ-фрормовании ячеистых структур. Используя метод акустической эмиссии можно контролировать параметры образования порового пространства структуры материалов. 
Разработанный метод исследования акустической эмиссии позволяет осуществлять контроль за структурообразованием пористых материалов получаемых по технологии внутреннего нагрева положительными источниками тепла.

\section{Выводы}

Данный метод основан на применении простых и доступных компьютерных технологий, что позволяет существенно снизить затраты на контрольно-измерительные приборы.

Для исследования влияния СВЧ - поля на свойства зернистых систем были проведены испытания на материалах, представленных в виде порошков: диатомита; микрокремнезема, полученного золь-гель методом из цеолитосодержащих пород; перлита.

Из анализа результатов экспериментальных данных следует, что после обработки увеличивается пористость зернистой системы, уменьшается насыпная плотность, меняется фрактальная размерность. Это обусловлено тем, что под действием внутреннего нагрева влага разрыхляет структуру частиц и способствует уменьшению коэфффициента теплопроводности.

Следовательно, для повышения эффрективности VIP - панелей рекомендуется проводить обработку зернистой системы в СВЧ - поле в течение 125 сек.

\section{Лumepamypa}

1. Дульнев Г. Н., Сигалова Г. В. Теплопроводность моно - м полидисперсных зернистых материалов. Строительная теплофизика. - М. Л. Энергия, 1966. - С. 40-47.

2. Селяев В. П., Осипов А. К., Куприяшкина Л. И., Седова А. А., Кечуткина Е. Л., Супонина Л. А. Возможность создания теплоизоляционных материалов на основе наноструктурированного 
микрокремнезема из диатомита // Наука: 21 Век. 2011. № 3(15). С. 76-86.

3. Selyaev V. P., Nurlybaev R. E., Neverov V. A., Aidarova S. B., Zhuginisov M. T., Murzagulova A. A. Nanostructured irregularity study by $X$-ray small-angle scattering. International Journal of Chemical Sciences. 2015, 13(3), pp.1421-1429.

4. Васильев Л. Л. Теплопроводность неметаллических зернистых систем // Строительная теплофизика. - М.; Л.: Энергия, 1966. - С. 48 - 56.

5. Дульнев Г. Н., Заричняк Ю. П. Теплопроводность смесей и композиционных материалов. Справочная книга Л., Энергия, 1974, $264 c$.

\section{References:}

1. Dulnev G. N., Sigalova G. V. Teploprovodnost mono $-m$ polidispersnykh zernistykh materialov. Stroitelnaya teplofizika. - M. L. Energiya, 1966. - S. 40-47.

2. Selyaev V. P., Osipov A. K., Kupriyashkina L. I., Sedova A. A., Kechutkina Ye. L., Suponina L. A. Vozmozhnost sozdaniya teploizolyatsionnykh materialov na osnove nanostrukturirovannogo mikrokremnezema iz diatomita // Nauka: 21 Vek. 2011. № 3(15). S. 76-86. 3. Selyaev V. P., Nurlybaev R. E., Neverov V. A., Aidarova S. B., Zhuginisov M. T., Murzagulova A. A. Nanostructured irregularity study by $X$-ray small-angle scattering. International Journal of Chemical Sciences. 2015, 13(3), pp.1421-1429.

4. Vasilev L. L. Teploprovodnost nemetallicheskikh zernistykh sistem // Stroitelnaya teplofizika. - M.; L.: Energiya, 1966. - S. 48 - 56.

5. Dulnev G. N., Zarichnyak Yu. P. Teploprovodnost smesey $i$ kompozitsionnykh materialov. Spravochnaya kniga L., Energiya, 1974, $264 \mathrm{~s}$. 